\title{
Health related quality of life of dialysis patients in Malaysia: Haemodialysis versus continuous ambulatory peritoneal dialysis
}

\author{
Naren Kumar Surendra ${ }^{1} \mathbb{D}$, Mohd Rizal Abdul Manaf ${ }^{1 *}$, Lai Seong Hooi ${ }^{2}$, Sunita Bavanandan², \\ Fariz Safhan Mohamad Nor ${ }^{4}$, Shahnaz Shah Firdaus Khan ${ }^{5}$, Loke Meng Ong ${ }^{6}$ and Abdul Halim Abdul Gafor ${ }^{7}$
}

\begin{abstract}
Background: Health related quality of life (HRQOL) is an important predictor of clinical outcomes for End Stage Renal Disease (ESRD) patients and to establish quality adjusted life years (QALYS) for economic evaluation studies. This study aims to measure the health utilities and to identify socio-demographic and clinical factors associated with HRQOL for haemodialysis (HD) and continuous ambulatory peritoneal dialysis (CAPD) in Malaysia.

Methods: A total of 141 patients (77 HD and 64 CAPD) from 1 federal and four state hospitals participated in this cross-sectional study. Patients were randomly selected from the National Renal Registry (NRR) using a stratified random sampling. The EQ-5D-3 L questionnaire was used to measure HRQOL. Variables investigated include dialysis modalities, sociodemographic characteristics, co-morbidities and biochemical markers. Utilities are measured on an ordinal scale of $0-1$, where 1 indicates full health and 0 indicates death.
\end{abstract}

Results: The mean utility scores were $0.854 \pm 0.181$ and $0.905 \pm 0.124(p>0.05)$ and the mean Visual Analogue Scale (VAS) scores were $76.2 \pm 12.90$ and $77.1 \pm 10.26(p>0.05)$ for HD and CAPD patients respectively. There was a significant difference in problems reported between HD (35.1\%) and CAPD (15.6\%) on usual activities dimension $(p=0.009)$. The proportion of patients having problems in the pain/discomfort domain in both modalities was high (34.0\%). Haemoglobin $(<10 \mathrm{~g} / \mathrm{dL})(p=0.003)$, number of co-morbidities $\geq 3(p=0.004)$ and wheelchair-bound status $(p<0.001)$ were significant predictors of poor HRQOL.

Conclusions: The present cross-sectional study shows that CAPD patients have a higher utility index score than HD patients but this was not statistically significant. The utilities index score may be used to calculate QALYs.

Keywords: Dialysis, Continuous ambulatory peritoneal dialysis, EQ-5D, Haemodialysis, Malaysia, Quality adjusted life year, Quality of life

\section{Background}

Health is defined by the World Health Organisation (WHO) as a state of complete physical, mental, and social well-being, and not merely the absence of disease or infirmity [1]. Since chronic diseases have an impact on health-related quality of life (HRQOL), this has become a key outcome measure in disease management $[2,3]$. HRQOL is a multi-dimensional model that includes

\footnotetext{
* Correspondence: mrizal@ppukm.ukm.edu.my

${ }^{1}$ Department of Community Health, Faculty of Medicine, Pusat Perubatan Universiti Kebangsaan Malaysia, Jalan Yaacob Latif, Bandar Tun Razak, 56000 Kuala Lumpur, Cheras, Malaysia

Full list of author information is available at the end of the article
}

domains related to physical, mental, emotional and social functioning.

Patients with end stage renal disease (ESRD) require renal replacement therapy (RRT) in the form of dialysis or a kidney transplant. Kidney transplantation may offer a nearly normal life and is considered the optimum treatment for eligible patients [4]. Despite kidney transplants from live and deceased donors, organ shortage remains a worldwide problem producing increasing waiting lists for transplantation and necessity for dialysis treatments [5]. Alternative dialysis modalities are haemodialysis (HD) and peritoneal dialysis (PD). In Malaysia, kidney transplantation is very

(C) The Author(s). 2019 Open Access This article is distributed under the terms of the Creative Commons Attribution 4.0 International License (http://creativecommons.org/licenses/by/4.0/), which permits unrestricted use, distribution, and reproduction in any medium, provided you give appropriate credit to the original author(s) and the source, provide a link to the Creative Commons license, and indicate if changes were made. The Creative Commons Public Domain Dedication waiver (http://creativecommons.org/publicdomain/zero/1.0/) applies to the data made available in this article, unless otherwise stated. 
limited and the majority of ESRD patients require dialysis, either HD or PD, to sustain life [6].

There were 37,183 patients dialysing in 2015 (1220 per million population) [7]. Dialysis is financed through a mixed public-private model. Almost all PD patients (97\%) were being treated in public settings [7]. There is a mixed financing system in dialysis provision in Malaysia with public financing is funded through the general taxation. The government also provide financial assistance to eligible patients through a few other agencies including SOCSO, a social welfare insurance body. Within the private sector, individuals can purchase health insurance on voluntary basis [6].

There are many complications associated with ESRD including anaemia, mineral bone disorders, cardiovascular disease and malnutrition [8]. As a result, ESRD has received increased attention as a leading public health problem. Estimates of the global burden of disease reported that kidney disease accounted for 1,129,000 deaths and 38,104,000 disability-adjusted life years (DALYs), making it the 12th highest cause of death (2.0\% of all deaths) and the 19th cause of disability (1.4\% of all DALY) [9].

ESRD patients on dialysis have impaired HRQOL which affects different domains of the patients' lives [10-17]. A wide range of general and disease-specific questionnaires have been utilised for evaluating the HRQOL of patients with ESRD $[10,18]$. In Malaysia, a limited number of studies were conducted to examine the HRQOL of dialysis patients using different questionnaires $[15,16,19]$. However, these studies were conducted mainly for patients' clinical management. HRQOL assessment is not only important for comparing outcomes of healthcare interventions but for supporting decisions regarding the allocation of resources [20]. EQ-5D, a generic instrument for measuring HRQOL, is commonly used for health economics studies [21]. EQ-5D output includes health profiles derived from the descriptive system, self-rated health status derived from the Visual Analogue Scale (VAS), and a weighted index derived using preference weights to produce quality-adjusted life-years (QALYs) [22]. QALY is recommended by the National Institute for Health and Clinical Excellence (NICE) as a measure of health benefit for their 'reference case' and to enable a standardised approach for comparing economic evaluations across different healthcare areas [23].

Hence, the aims of the study are to estimate health utilities, to compare the HRQOL of HD and CAPD patients, and to identify factors associated with HRQOL through an analysis of socio-demographic and clinical variables using EQ-5D-3 L questionnaire.

\section{Methods}

\section{Sample}

This was a multi-centre cross sectional study conducted as part of the Cost Utility Analysis of End Stage Renal
Disease Treatment in Ministry of Health (MOH) Dialysis centres, Malaysia: HD versus CAPD. The sampling frame for the selection of participating centres was $\mathrm{MOH}$ state hospitals that submit dialysis patients' data to the National Renal Registry (NRR). A principal site investigator, sub-investigators and research assistants were appointed at each centre. Patients were eligible if they were above 18 years old, commenced dialysis between 2011 and 2015 and dialysis treatment is subsidised by $\mathrm{MOH}$. Patients were excluded if they died, underwent kidney transplant, switched dialysis modality or transferred to a new centre during the study period. Patients were sampled by a stratified random sampling using the list of prevalent dialysis patients obtained from NRR. All patients provided written informed consent for participation in this study. One hundred and seventy three dialysis patients (90 HD and $83 \mathrm{CAPD}$ ) were recruited from 1 federal and 4 large state hospitals. The study period for cost utility analysis was from 1st October 2016 to 30th September 2017. HRQOL data was collected during the last quarter of the study period (May 2017 to September 2017).

\section{Recruitment and data collection procedures}

Consent was taken by the principal investigator or the principal site investigator at each site. Upon signing the consent form, socio-demographic details were collected including education level, monthly household income, body mass index (BMI) and employment status. Duration on dialysis, and co-morbidities were assessed from patients' medical records.. Patients were described of having hypertension and/or diabetes through self-reporting diagnosed by medical personnel or on respective medication. For Systemic lupus erythematosus (SLE), it was identified according to the American College of Rheumatology (ACR) 1997 guidelines. A patient who fulfilled least four of the eleven criteria was accepted as having lupus [24]. Patients were classified as having cardiovascular disease (CVD) when they had history of coronary artery or cerebrovascular disease as diagnosed by medical personnel. A positive HBsAg test result indicates that the patient is infected with Hepatitis $B$ and a positive anti-HCV result indicates that the patient is infected with Hepatitis C. Laboratory test results were also recorded including serum calcium $(\mathrm{mmol} / \mathrm{L})$, haemoglobin $(\mathrm{g} / \mathrm{dL})$, serum albumin $(\mathrm{g} / \mathrm{L})$ and dialysis adequacy $(\mathrm{Kt} /$ V). Patients' HRQOL was measured using the EQ-5D-3 L questionnaire developed by the EuroQol group. This questionnaire is validated for Malaysia's healthcare setting [22]. The EQ-5D questionnaire comprises a visual analog scale (VAS) and an EQ-5D descriptive system. Respondent's self-appraised health status is captured using VAS which is graduated in 10-points increments from 0 (worst imaginable health state) to 100 (best imaginable health 
state). The descriptive system contains 5 health dimensions; mobility, self-care, usual activities, pain/discomfort, and anxiety/depression. It can be used as a health profile or transformed into an index score. The questionnaire is available in four languages including English, Malay, Chinese and Tamil. Since the questionnaire is self-administered, patients were asked to complete the form during a regular HD session (for HD) or scheduled clinic visit (for CAPD). When patients had trouble reading, writing or understanding the questionnaires, a trained research assistant provided assistance.

\section{Statistical analysis}

Continuous variables were expressed as mean \pm standard deviation (SD). Discrete variables were reported as frequency and percentage. Chi-square test or Fisher's Exact test were used for group comparisons (HD and CAPD) where appropriate. For EQ-5D-3 L utility index and VAS, the distributions of scores were reported as the mean $\pm(\mathrm{SD})$ and median, minimum, maximum, and the percentage of problems reported. Malaysian tariff developed by Faridah Aryani et al. was used to convert the utility score (N3 Rescaled VAS scoring algorithm) [23].

In the bivariate analysis, continuous independent variables were converted into categorical variables since there was a non-linear relationship between the dependent variable (utility index score and VAS score) and the continuous independent variables. Continuous variables were coded using either recommended clinically meaningful values or means/medians when the former was absent. Since the data of utility scores and VAS score were not normally distributed, on the basis of the Kolmogorov-Smirnov and the Shapiro-Wilk tests of normality $(P<0.001)$, non-parametric statistical tests were performed. In the multivariate analysis, the one-way analysis of covariance (ANCOVA) was used. Only statistically significant factors in the bivariate analysis were entered into the model. The model fit was tested according to the following assumptions; a) random sample, b) independence of observations c) approximate normality and d) equal variance. Assumptions a and b were related to study design which were fulfilled. Normality and equal variance (homoscedasticity) assumptions were tested using scatter plots and Levene's test of the standardised residuals. A $p$ value $<0.05$ was considered significant. All tests were conducted using SPSS version 24 .

\section{Ethics approval}

Ethical approvals were sought from the Institutional review board of UKMMC (Fundamental FF-2016-288) and Medical Research Ethics committee (MREC) (NMRR-16-1341-30,856). This study was also registered at ClinicalTrials.gov (NC T02862717).

\section{Results}

One hundred and forty-one patients answered the EQ-5D-3 L questionnaire. The study patient characteristics are shown in Table 1.

The mean age of the patients was $53.7 \pm 14.20$ years. Patients were predominantly male (55.3\%), from Malay ethnicity (46.1\%), with household income below RM3000 per month (80.9\%), attained secondary education (59.6\%) and unemployed $(73.0 \%)$. The mean dialysis duration was $3.9 \pm 1.43$ years. Majority of the patients had hypertension $(58.2 \%)$ and $48.9 \%$ had diabetes mellitus. Twenty patients (14.2\%) had CVD (14.2\%) and 51.8\% were in normal BMI category. The mean serum calcium, haemoglobin and serum albumin was $2.243 \pm 0.185 \mathrm{mmol} / \mathrm{L}, 10.6 \pm 1.33 \mathrm{~g} / \mathrm{dL}$ and $37 \pm 5.5 \mathrm{~g} / \mathrm{L}$ respectively. Dialysis adequacy $(\mathrm{Kt} / \mathrm{V}) \mathrm{can}$ not be directly compared between HD and CAPD. HD patients had mean Kt/V of $1.66 \pm 0.28$ per dialysis and CAPD patients had mean $\mathrm{Kt} / \mathrm{V}$ of $1.90 \pm 0.37$ per week. The groups differed significantly in terms of Hepatitis B and Hepatitis $C$ status $(p<0.001)$ and mean serum albumin $(p<0.001)$. However, they did not differ in socio-demographic or other clinical characteristics.

\section{Utility index score and VAS score}

The overall mean utility score for all patients was $0.877 \pm$ $0.160(0.905 \pm 0.124$ for CAPD and $0.854 \pm 0.181$ for HD, $p=0.157)$ and the mean VAS score was $76.6 \pm 11.76$ $(77.1 \pm 10.26$ for CAPD and $76.2 \pm 12.90$ for HD, $p=$ $0.921)$. Statistically significant differences were not found between HD and CAPD patients in both utility index score and VAS score (Table 2).

\section{Correlation between utility score and VAS score}

Assuming non-normal distribution of either one of the variables, a non-parametric test was used (Spearman Rank correlation) to determine the relationship between the predicted utility score and VAS score. There was a moderate, positive correlation between utility score and VAS score which was statistically significant $(r=0.677, p<0.001)$.

\section{EQ-5D-3 L health domains}

Table 3 shows the proportion of HD and CAPD patients reporting problems in each EQ-5D-3 L dimension. The highest proportion of problems was reported in the pain/ discomfort dimension with 32.5\% of HD patients and 35.9\% of CAPD patients reporting problems. The lowest proportion of reported problems was observed in the self-care dimension, $11.3 \%$ of total patients. There was a significant difference of reported problems between HD and CAPD patients on usual activities dimension $(p=0.009)$ with 35.1 and $15.6 \%$ of patients reporting problems respectively. 
Table 1 Patient characteristics

\begin{tabular}{|c|c|c|c|c|}
\hline Characteristics & All patients $(n=141)$ & $\mathrm{HD}(n=77)$ & CAPD $(n=64)$ & $P$ value \\
\hline$\overline{\text { Age (years), mean (SD) }}$ & $53.7(14.20)$ & $53.9(14.90)$ & $53.5(13.43)$ & $0.830^{\mathrm{a}}$ \\
\hline Age group, $\mathrm{n}(\%)$ & & & & $0.100^{b}$ \\
\hline Young, 18-45 & $36(25.5)$ & $19(24.7)$ & $17(26.6)$ & \\
\hline Middle aged, 46-65 & $75(53.2)$ & $41(53.2)$ & $34(53.1)$ & \\
\hline Elderly, $>65$ & $30(21.3)$ & $17(22.1)$ & $13(20.3)$ & \\
\hline Gender, n (\%) & & & & $0.066^{b}$ \\
\hline Male & $78(55.3)$ & $48(62.3)$ & $30(46.9)$ & \\
\hline Female & $63(44.7)$ & $29(37.7)$ & $34(53.1)$ & \\
\hline Ethnicity, n (\%) & & & & $0.335^{\mathrm{b}}$ \\
\hline Malay & $65(46.1)$ & $32(41.6)$ & $33(51.6)$ & \\
\hline Chinese & $51(36.2)$ & $32(41.6)$ & $19(29.7)$ & \\
\hline Indian/others & $25(17.7)$ & $13(16.9)$ & $12(18.8)$ & \\
\hline Household income per month (RM), n (\%) & & & & $0.453^{b}$ \\
\hline$<3000$ & $114(80.9)$ & $64(83.1)$ & $50(78.1)$ & \\
\hline$\geq 3000$ & $27(19.1)$ & $13(16.9)$ & $14(21.9)$ & \\
\hline Education level, n (\%) & & & & $0.100^{b}$ \\
\hline Primary & $39(27.7)$ & $19(24.7)$ & $20(31.3)$ & \\
\hline Secondary & $84(59.6)$ & $44(57.1)$ & $40(62.5)$ & \\
\hline Tertiary & $18(12.8)$ & $14(18.2)$ & $4(6.3)$ & \\
\hline Occupation, n (\%) & & & & $0.634^{b}$ \\
\hline Employed & $38(27.0)$ & $22(28.6)$ & $16(25.0)$ & \\
\hline Unemployed/Retired/Housewife & $103(73.0)$ & $55(71.4)$ & $48(75.0)$ & \\
\hline Primary Renal disease, n (\%) & & & & $0.966^{\mathrm{b}}$ \\
\hline Diabetes mellitus & $65(46.1)$ & $34(44.2)$ & $31(48.4)$ & \\
\hline Hypertension & $32(22.7)$ & $17(22.1)$ & $15(23.4)$ & \\
\hline SLE / Glomerulonephritis & $24(17.0)$ & $14(18.2)$ & $10(15.6)$ & \\
\hline Polycystic kidney & $7(5.0)$ & $4(5.2)$ & $3(4.7)$ & \\
\hline Unknown cause /Others & $13(9.2)$ & $8(10.4)$ & $5(7.8)$ & \\
\hline Dialysis duration (years), mean (SD) & $3.9(1.43)$ & $4.1(1.46)$ & $3.7(1.37)$ & $0.114^{\mathrm{a}}$ \\
\hline \multicolumn{5}{|l|}{ Co-morbidities, n (\%) } \\
\hline Diabetes mellitus & $69(48.9)$ & $36(46.8)$ & $33(51.6)$ & $0.570^{b}$ \\
\hline Hypertension & $82(58.2)$ & $46(59.7)$ & $36(56.3)$ & $0.654^{b}$ \\
\hline SLE & $6(5.0)$ & $3(3.9)$ & $3(4.7)$ & $1.000^{c}$ \\
\hline CVD & $20(14.2)$ & $13(16.9)$ & $7(10.9)$ & $0.314^{b}$ \\
\hline Hepatitis B infection & $10(7.1)$ & $10(13.0)$ & $0(0)$ & $<0.001^{b}$ \\
\hline Hepatitis C infection & $6(4.3)$ & $6(7.8)$ & $0(0)$ & $0.032^{c}$ \\
\hline Body Mass Index $\left(\mathrm{kg} / \mathrm{m}^{2}\right), n(\%)$ & & & & $0.134^{b}$ \\
\hline Underweight (< 18.5) & $16(11.3)$ & $13(16.9)$ & $3(4.7)$ & \\
\hline Normal weight (18.5-24.9) & $73(51.8)$ & $37(48.1)$ & $36(56.3)$ & \\
\hline Overweight (25.0-29.9) & $31(22.0)$ & $15(19.5)$ & $16(25.0)$ & \\
\hline Obese $(\geq 30)$ & $21(14.9)$ & $12(15.6)$ & $9(14.1)$ & \\
\hline \multicolumn{5}{|l|}{ Biochemistry, mean (SD) } \\
\hline Serum calcium (mmol/L) & $2.23(0.185)$ & $2.21(0.20)$ & $2.27(0.16)$ & $0.060^{\mathrm{a}}$ \\
\hline Haemoglobin (g/dL) & $10.6(1.33)$ & $10.7(1.1)$ & $10.6(1.5)$ & $0.781^{\mathrm{a}}$ \\
\hline
\end{tabular}


Table 1 Patient characteristics (Continued)

\begin{tabular}{|c|c|c|c|c|}
\hline Characteristics & All patients $(n=141)$ & $\mathrm{HD}(n=77)$ & CAPD $(n=64)$ & $P$ value \\
\hline Serum albumin $(g / L)$ & $37(5.5)$ & $39(4.5)$ & $35(5.6)$ & $<0.001^{\circ}$ \\
\hline Dialysis adequacy (Kt/N) & - & $1.66(0.28)$ per dialysis & 1.90 (0.37) per week & - \\
\hline Wheelchair-bound & & & & $1.000^{c}$ \\
\hline Yes & $5(2.8)$ & $3(3.9)$ & $2(3.1)$ & \\
\hline No & $136(97.2)$ & $74(96.1)$ & $62(96.9)$ & \\
\hline
\end{tabular}

HD Haemodialysis, CAPD Continuous ambulatory peritoneal dialysis, CVD cardiovascular disease, SD standard deviation, SLE Systemic lupus erythematosus ${ }^{\mathrm{a}}$ Independent t-test; ${ }^{\mathrm{b}}$ Chi-Square test; ${ }^{\mathrm{C}}$ Fisher's exact test

\section{Bivariate analysis of independent factors and utility index score and VAS score}

Table 4 shows the association of the independent factors with the EQ-5D-3 L utility score and VAS score. Factors significantly associated with HRQOL include presence of CVD, number of co-morbidities, haemoglobin, wheelchair-bound, age, diabetes mellitus and serum albumin.

\section{Multivariate analysis of independent factors and utility index score}

To adjust for the factors that were significantly associated with utility index score and VAS score in the bivariate analysis, one-way ANCOVA was used. The model for utility index score (Table 5) confirmed that the significant predictors of lower EQ-5D utility score included number of co-morbidities $\geq 3 \quad(p<0.004)$, low haemoglobin level $<10 \mathrm{~g} / \mathrm{dL}(p=0.002)$ and wheelchairbound $(p<0.001)$. Wheelchair-bound status $(p<0.001)$ was a significant predictor of the lower VAS score (Table 6).

\section{Discussion}

The present study investigates the HRQOL of HD and CAPD patients in 1 federal and 4 state hospitals in Malaysia. Statistically significant differences of utility index score and VAS score were not found between HD and CAPD patients. These findings are inconsistent with two earlier publications from Malaysia on dialysis related HRQOL. Liu et al. conducted a survey on 6908 HD and CAPD patients using Spitzer's QOL index and HD was found to be a significant predictor for low HRQOL score [15]. In another study by Lui et al., a survey on 1332 dialysis patients was conducted at 15 dialysis centres using the World Health Organisation Quality of Life questionnaire (WHOQOL-BREF) and HD was identified as one of the significant predictors for low HRQOL score [16] The differences in study findings could be explained by several reasons. The large sample size in the previous studies probably enabled small differences to become statistically significant. In addition, the participation of a relatively large number of centres $(n=15)$ is perceived to introduce more variations in the results. The instruments used to measure the HRQOL were also different. However, the present study has provided the necessary utility index scores to calculate the QALY for a cost utility analysis to be carried out.

These results were consistent with other literature that used EQ-5D as their study instrument (or along with other study instruments). Among patients participating in a prospective cohort study on the adequacy of dialysis, de Wit et al. could not demonstrate differences between $\mathrm{HD}$ and $\mathrm{PD}$ patients using four different instruments including EQ-5D [25]. In Singapore, the closest country in terms of patients' socio-demographic characteristics, dialysis modality has no impact on the health utility of HD and CAPD patients [17]. There are also other studies showing similar HRQOL between HD and CAPD patients using a variety of other instruments [26-33]. These findings were supported by a comprehensive systematic review by Liem et al. on preference

Table 2 Utility index score and Visual analogue score, haemodialysis and versus continuous ambulatory peritoneal dialysis

\begin{tabular}{llll}
\hline Score & All patients $(n=141)$ & HD $(n=77)$ & CAPD $(n=64)$ \\
\hline $\begin{array}{lll}\text { Utility index score } \\
\text { mean (SD) }\end{array}$ & $0.877(0.160)$ & $0.854(0.181)$ & $0.905(0.124)$ \\
$\quad$ Median (IQR) & $0.880(0.202)$ & $0.880(0.204)$ & $1.000(0.189)$ \\
$\quad$ Minimum, Maximum & $0.290,1.000$ & $0.290,1.000$ & $0.564,1.000$ \\
VAS score & & & $77.1(10.26)$ \\
mean (SD) & $76.6(11.76)$ & $76.2(12.90)$ & $80.0(15.0)$ \\
Median (IQR) & $80.0(15.0)$ & $80.0(15.0)$ & 50,90 \\
\hline
\end{tabular}

${ }^{a}$ Mann Whitney $\mathrm{U}$ test; IQR: Interquartile range 
Table 3 Proportions of problems reported on each EQ-5D dimension

\begin{tabular}{lllll}
\hline Health Dimension & All patients $(n=141)$ & HD $(n=77)$ & CAPD $(n=64)$ & $P$ value \\
\hline Mobility, $\mathrm{n}(\%)$ & $37(26.2)$ & $23(29.9)$ & $14(21.9)$ & $5(7.8)$ \\
Self-Care, $\mathrm{n}(\%)$ & $16(11.3)$ & $11(14.3)$ & $10(15.6)$ & $>0.05^{\mathrm{a}}$ \\
Usual Activities, $\mathrm{n}(\%)$ & $37(26.2)$ & $27(35.1)$ & $23(35.9)$ & $\mathbf{0 . 0 0 9 ^ { \mathrm { a } }}$ \\
Pain / Discomfort, $\mathrm{n}(\%)$ & $48(34.0)$ & $25(32.5)$ & $9(14.1)$ & $>0.05^{\mathrm{a}}$ \\
Anxiety / Depression, $\mathrm{n}(\%)$ & $20(14.2)$ & $11(14.3)$ & $>0.05^{\mathrm{a}}$ \\
\hline
\end{tabular}

${ }^{a}$ Chi-squared test (x 2)

based quality of life of patients on RRT. They did a meta-analysis of 27 articles including utilities from time-trade-off (TTO), standard gamble (SG), and EQ-5D studies and found that there were no statistically significant differences in HRQOL between HD and PD patients [34]. The insignificant differences in HRQOL suggests that the relative cost-effectiveness of the two dialysis modalities in Malaysia would be mainly determined by their associated costs.

A significant difference of problems reported in the usual activity domain was identified between the two modalities in this study where CAPD patients reported less problems as compared to HD patients. This is not surprising since PD patients scored higher in physical activity domain in previous literature [35-39]. CAPD is often perceived as the easier and less burdensome dialysis modality since dialysis may be performed at home. In contrast, HD patients have to travel to their respective dialysis centres to get treatment and would usually remain there for four hours, thus restricting their daily activities. However findings are mixed; some researchers showed that patients on HD scored better in physical activity domain as compared to patients on PD [28, 33, 40, 41]. In fact, HD patients tend to improve in their daily activities as they continue the treatment [33].

The high proportion of problems reported in pain/discomfort domain is of concern. It was observed in patients on both modalities. There are many factors that can lead to either acute or chronic pain in patients on HD, as well as in patients on CAPD. Pain/discomfort have been shown to influence the overall quality of life HD and CAPD patients [32, 42]. Theoretically this could be attributed to the pain due to dialysis access and needles, as well as existing co-morbidities. It would be hypothetical to come to any kind of conclusion about the reasons for the high proportion of pain/discomfort found in this group of patients. This result indicates that a separate study with the focus on body pain should be conducted to address the limited studies found in literature.

In the one-way ANCOVA, low haemoglobin level $(<10 \mathrm{~g} / \mathrm{dL})$, number of co-morbidities $\geq 3$ and wheelchairbound status were significant predictors for poor HRQOL. Similar associations were observed in previous studies [15-17, 43-47]. Lopes et al. found that co-morbidity, and low haemoglobin level were among the factors independently and significantly associated with impaired physical health in $9000 \mathrm{HD}$ patients from seven countries [43]. Finkelstein et al. (2009) asserted that the energy/vitality domain, the physical composite score of the SF-36, and the general health score of 1200 patients with stage 3, 4, and 5 Chronic kidney disease (CKD) increased significantly with hemoglobin levels elevation [44]. A study of PD patients using EQ-5D instrument showed that significant predictors of high VAS score included reduced co-morbidities and use of erythropoietin [45]. Recently, a cross sectional survey by Eriksson et al. among CKD patients across Europe emphasised that after stratification by anaemia status, impairment was consistently lower for anaemic than non-anaemic CKD patients across various measurement scales [46].

The impact of CVD in dialysis patients is well established. CVD is a predictor of poor HRQOL in patients with ESRD [47]. Registry studies confirmed that CVD is an independent risk factor for and the leading cause of death in dialysis patients, accounting for nearly $50 \%$ of deaths in this population [7, 45-49]. However, CVD alone was not found to be a significant predictor of HRQOL in this research possibly due to the presence of additional co-morbidities. Wheelchair-bound patients have obvious restrictions in morbidity and physical functioning. They were more likely to report poor health than people without a disability $[50,51]$.

Remarkably, the mean utility score for patients in this study was high (overall $=0.877, \mathrm{HD}=0.854, \mathrm{CAPD}=0.905$ ) compared to other literature using EQ-5D as their main instrument. Typical values of prevalent dialysis patients are in the $0.40-0.70$ range $[14,17,25,34]$. These observations could be attributed to several factors. First and foremost, a Malaysian value set was used to calculate utility index scores. There are different value sets developed in different countries and each value set carry different weights. For example, 11,112 (mobility $=1$, self-care $=1$, usual activities $=1$, pain/discomfort $=1$, and anxiety/depression $=2$ ), yields $0.852,0.782$ and 0.799 using Malaysian value set, UK value set and Spanish value set respectively (VAS as referent). The methodological dissimilarities among other cultural divergence in the valuation studies across countries conceivably 
Table 4 Bivariate analysis of independent factors and utility index score/visual analogue scale

\begin{tabular}{|c|c|c|c|c|}
\hline Characteristics & Utility index score, mean (SD) & $p$ value & VAS score, mean (SD) & $p$ value \\
\hline Modality & & $0.157^{\mathrm{a}}$ & & $0.921^{a}$ \\
\hline $\mathrm{HD}, n=77$ & 0.854 & & 76.2 & \\
\hline CAPD, $n=64$ & 0.905 & & 77.1 & \\
\hline Age group, years & & $0.117^{\mathrm{b}}$ & & $0.032^{\mathrm{b}}$ \\
\hline Young, $18-45, n=36$ & 0.924 & & 80.97 & \\
\hline Middle aged, $46-65 n=75$ & 0.850 & & 74.66 & \\
\hline Elderly, $>65, n=30$ & 0.871 & & 75.53 & \\
\hline Gender & & $0.764^{\mathrm{a}}$ & & $0.892^{a}$ \\
\hline Male, $n=78$ & 0.871 & & 76.06 & \\
\hline Female, $n=63$ & 0.884 & & 77.29 & \\
\hline Ethnicity & & $0.497^{\mathrm{a}}$ & & $0.787^{\mathrm{a}}$ \\
\hline Malay, $n=65$ & 0.873 & & 76.23 & \\
\hline Non-Malay, $n=76$ & 0.880 & & 76.93 & \\
\hline Household income per month (RM) & & $0.453^{\mathrm{a}}$ & & $0.191^{\mathrm{a}}$ \\
\hline$\geq 3000, n=27$ & 0.908 & & 79.26 & \\
\hline$<3000, n=114$ & 0.870 & & 75.98 & \\
\hline Education level & & $0.376^{\mathrm{b}}$ & & $0.593^{b}$ \\
\hline Primary, $n=39$ & 0.874 & & 74.87 & \\
\hline Secondary, $n=84$ & 0.871 & & 77.64 & \\
\hline Tertiary, $n=18$ & 0.911 & & 75.56 & \\
\hline Occupation & & $0.261^{\mathrm{a}}$ & & $0.070^{\mathrm{a}}$ \\
\hline Employed, $n=38$ & 0.911 & & 79.82 & \\
\hline Unemployed, $n=103$ & 0.864 & & 75.43 & \\
\hline Dialysis duration & & $0.508^{\mathrm{a}}$ & & $0.098^{\mathrm{a}}$ \\
\hline$\geq 4.0$ years, $=62$ & 0.891 & & 79.08 & \\
\hline$<4.0$ years, $n=79$ & 0.865 & & 74.67 & \\
\hline Diabetes mellitus & & $0.191^{a}$ & & $0.035^{a}$ \\
\hline Diabetic, $n=69$ & 0.857 & & 74.09 & \\
\hline Non-diabetic, $n=72$ & 0.896 & & 79.03 & \\
\hline CVD & & $0.001^{\mathrm{a}}$ & & $0.028^{a}$ \\
\hline Present, $n=20$ & 0.739 & & 71.10 & \\
\hline Absent, $n=121$ & 0.900 & & 77.52 & \\
\hline Number of co-morbidities & & $<0.001^{\mathrm{a}}$ & & $0.001^{a}$ \\
\hline$<3, n=120$ & 0.905 & & 78.17 & \\
\hline$\geq 3, n=21$ & 0.714 & & 67.71 & \\
\hline Body mass Index $\left(\mathrm{kg} / \mathrm{m}^{2}\right)$ & & $0.834^{\mathrm{a}}$ & & $0.929^{\mathrm{a}}$ \\
\hline$<25, n=89$ & 0.877 & & 76.89 & \\
\hline$\geq 25, n=52$ & 0.877 & & 76.13 & \\
\hline Serum calcium (mmol/L) & & $0.340^{\mathrm{a}}$ & & $0.079^{\mathrm{a}}$ \\
\hline$<2.20, n=53$ & 0.850 & & 73.91 & \\
\hline$\geq 2.20, n=88$ & 0.893 & & 78.24 & \\
\hline Haemoglobin ( $\mathrm{g} / \mathrm{dL})$ & & $0.013^{\mathrm{a}}$ & & $0.164^{\mathrm{a}}$ \\
\hline Low $_{1}<10, n=41$ & 0.829 & & 74.76 & \\
\hline High, $\geq 10, n=100$ & 0.896 & & 77.37 & \\
\hline
\end{tabular}


Table 4 Bivariate analysis of independent factors and utility index score/visual analogue scale (Continued)

\begin{tabular}{|c|c|c|c|c|}
\hline Characteristics & Utility index score, mean (SD) & $p$ value & VAS score, mean (SD) & $p$ value \\
\hline Serum albumin $(g / L)$ & & $0.063^{a}$ & & $0.034^{a}$ \\
\hline Low $_{1}<35, n=50$ & 0.836 & & 73.10 & \\
\hline High, $\geq 35, n=91$ & 0.899 & & 78.54 & \\
\hline Wheelchair-bound & & $<0.00^{a}$ & & $<0.001^{a}$ \\
\hline Yes, $n=5$ & 0.462 & & 48.00 & \\
\hline No, $n=136$ & 0.892 & & 77.66 & \\
\hline
\end{tabular}

${ }^{\mathrm{a}}$ Mann Whitney $\mathrm{U}$ test ${ }^{\mathrm{b}}$ Kruskal-Wallis test

prompted the difference in the utility index scores [52]. The higher utility scores from the Malaysian value set are also related to the valuation study where patient valuations was used instead of the general population [23]. Valuation studies in Singapore, Thailand, and the UK used the general population as respondents [53]. A similar observation was reported in Sweden when higher utility scores were derived from the study using patient valuations instead of the general population [54]. Zhao et al. supported that country-specific tariff should be used since there were significant differences among the three national tariff sets (Chinese, UK, Japanese) [55]. Another possible reason is that, half of the respondents in this study reported no problems in all health states (11111). Patients in this study were perceived to receive better care since they were recruited from state hospitals. The decision to use the Malaysian value set is justified. In a study by Endarti et al. that compared EQ-5D-3 L index scores using Malaysian, Singaporean, Thai, and the UK value sets in Indonesian cervical cancer patients, the Malaysian value set achieved the highest interrelation intraclass correlation coefficients (ICC) versus VAS scores

Table 5 Regression coefficients in generalised linear model of utility index score

\begin{tabular}{lll}
\hline Characteristics & Utility index score & \\
\cline { 2 - 3 } Adj. b $(95 \% \mathrm{Cl})$ & \\
\hline Present & $-0.070(-0.142,0.002)$ & 0.058 \\
Absent (Ref) & - & - \\
Haemoglobin (g/dL) & & \\
Low, $<10$, & $-0.073(-0.118,-0.027)$ & $\mathbf{0 . 0 0 2}$ \\
High, $\geq 10$ (Ref) & - & - \\
Wheelchair-bound & & $<\mathbf{0 . 0 0 1}$ \\
Yes & $-0.368(-0.484,-0.253)$ & - \\
$\quad$ No (Ref) & - & $\mathbf{0 . 0 0 4}$ \\
Number of co-morbidities & & - \\
$\geq 3$ & $-0.106(-0.179,-0.034)$ & \\
$<3$ (Ref) & - &
\end{tabular}

Adj. $b$ : Standardised coefficients, CVD: Cardiovascular disease Adjusted $\mathrm{R}^{2}: 39 \%$ (F 23.667; $p<0.001$ ) compared with the ICCs of the other three scores versus VAS scores [52].

This study has several limitations. First, a causal relationship could not be established between certain variables and HRQOL since it was a cross-sectional study. Second, this study was conducted in only five large hospitals which could have had a positive influence on the overall HRQOL. The experiences of these patients may differ with those of patients managed in other dialysis centres e.g. in district hospitals. Future HRQOL study among dialysis patients using EQ-5D questionnaire in Malaysia should include more centres to introduce variability in the sample as shown in previous studies. Besides, the sample size is relatively small as compared to

Table 6 Regression coefficients in generalised linear model of VAS score

\begin{tabular}{|c|c|c|}
\hline \multirow[t]{2}{*}{ Characteristics } & \multicolumn{2}{|l|}{ VAS score } \\
\hline & Adj. b (95\% Cl) & $p$ value \\
\hline \multicolumn{3}{|l|}{ Age group } \\
\hline Middle aged, 46-65 & $-3.419(-7.283,0.986)$ & 0.134 \\
\hline Elderly, $>65$ & $-5.295(-10.602,0.012)$ & 0.051 \\
\hline Young, 18-45 (Ref) & - & - \\
\hline \multicolumn{3}{|l|}{ CVD } \\
\hline Present & $0.487(-5.531,6.506)$ & 0.873 \\
\hline Absent (Ref) & - & - \\
\hline \multicolumn{3}{|l|}{ Serum albumin (g/L) } \\
\hline Low $_{1}<35$ & $-2.259(-6.211,1.513)$ & 0.233 \\
\hline High, $\geq 35$ (Ref) & - & - \\
\hline \multicolumn{3}{|l|}{ Wheelchair-bound } \\
\hline Yes & $-25.567(-35.132,-16.003)$ & $<0.001$ \\
\hline No (Ref) & - & - \\
\hline \multicolumn{3}{|c|}{ Number of co-morbidities } \\
\hline$\geq 3$ & $-5.963(-12.082,0.155)$ & 0.056 \\
\hline$<3$ (Ref) & - & - \\
\hline \multicolumn{3}{|l|}{ Diabetes mellitus } \\
\hline Diabetic & $-0.715(-3.919,3.568)$ & 0.926 \\
\hline Non-diabetic & - & - \\
\hline
\end{tabular}

Adj. b: Standardised coefficients, CVD Cardiovascular disease Adjusted $\mathrm{R}^{2}: 27 \%$ (F 8.269; $p<0.001$ ) 
other studies. Lastly. there are other factors that were not studied including cultural, religious practices and environment which could affect HRQOL as indicated in the low adjusted $R^{2}$.

\section{Conclusions}

In conclusion, the present study provides an understanding of overall HRQOL of HD and CAPD patients using the EQ-5D questionnaire. The results show that dialysis modality had no impact on HRQOL although PD patients scored a higher utility index. Other factors including low haemoglobin level, number of co-morbidities and wheelchair-bound status were significant predictors of low HRQOL. Health domains profoundly affected include usual activities and pain/discomfort domains. This study indicates that the EQ-5D questionnaire can both measure patients' HRQOL in local settings and produce QALYs as key outcome measure in economic evaluation studies.

\section{Abbreviations \\ BMl: Body mass index; CAPD: Continuous ambulatory peritoneal dialysis; CKD: Chronic kidney disease; CVD: Cardiovascular disease; DALY: Disability adjusted life year; ESRD: End stage renal disease; GFR: Granular filtration rate; HD: Haemodialysis; HRQOL: Health related quality of life; MOH: Ministry of Health; PD: Peritoneal dialysis; QALY: Quality adjusted life year; QOL: Quality of life; RRT: Renal replacement therapy; SD: Standard deviation; SG: Standard gamble; SLE: Systemic lupus erythematosus; TTO: Time trade off; VAS: Visual analogue scale; VIF: Variance inflation factors; WHO: World Health Organisation; WHOQOL-BREF: World Health Organisation Quality of Life questionnaire}

\section{Acknowledgements \\ The authors would like to gratefully acknowledge all the people that have made this study possible. First and foremost, we would like to thank the sub principal investigators and research assistants comprise of nurses and medical assistants at each centres for their valuable input and data collection; Dr. Liu Wen Jiun, Ms. Jamilah Sarif, Mr. Norisham bin Mohd Dom (Hospital Sultanah Aminah), Dr. Kiren Kaur A/P Bhajan Singh, Ms. Rozana Bt Zainol Rasid, Ms. Bistari Binti Zubir (Hospital Tengku Ampuan Afzan), Mr. Amirul Nizam bin Mohtar, Mr. Mohd Patrizal bin Zahari, Ms. Jamaiyah binti Supar, Ms. Vijaya A/P Lakayan (Hospital Kuala Lumpur), Ms. Lim Siew Kim, Mr. Khairul Nul Hakim bin Hazman, Norhazliza binti Hashim Hospital Pulau Pinang, Mr. Ratneswaran A/L Naganathan, Ms. Noriah binti Othman (Hospital Tengku Ampuan Rahimah). Second, we would like to acknowledge Dato' Dr. Tan Chwee Choon, former Head of Nephrology Service, Ministry of Health Malaysia and Datuk Dr. Ghazali Ahmad, Head of Nephrology Department, Hospital Kuala Lumpur for providing us with their able assistance and allowing us to conduct this research. Besides, we would like to thank National Renal Registry, in particular, Madam Lee Day Guat in providing patients' list for sampling. Finally, the authors thank the Director General of Health in Malaysia for permission to publish this paper.}

\section{Funding}

This research received fundamental research grant from Pusat Perubatan Universiti Kebangsaan Malaysia and an external research grant from the Malaysian Society of Nephrology.

\section{Availability of data and materials}

The datasets used and/or analysed during the current study are available from the corresponding author on request.

\section{Authors' contributions}

All authors were responsible for identifying the research question, study design and drafting the protocol. NK performed literature search, developed the methodology, executed the data collection and wrote paper. MR supervised the protocol development, methodology development and actual research. LS was involved in planning, supervised the data collection at the site, verified the data and contributed important reagents especially on methodology and collator. S, FS, SS and LM were involved in the planning, supervised the data collection at their respective sites and verified the data. AH supervised the actual research and revising the manuscript critically for important intellectual content. All authors provided comments and have read and approved the final version.

\section{Ethics approval and consent to participate}

Ethics approvals were obtained from Pusat Perubatan Universiti Kebangsaan Malaysia (JEP-2016-360) and Malaysian Medical Research Ethics Committee (NMRR-16-1341-30,856). All research participants were provided with the Patient Information Sheet (PIS) and gave their permission to be part of the study by signing the informed consent form.

\section{Consent for publication}

Not applicable

\section{Competing interests}

The authors declare that they have no competing interests.

\section{Publisher's Note}

Springer Nature remains neutral with regard to jurisdictional claims in published maps and institutional affiliations.

\section{Author details}

${ }^{1}$ Department of Community Health, Faculty of Medicine, Pusat Perubatan Universiti Kebangsaan Malaysia, Jalan Yaacob Latif, Bandar Tun Razak, 56000 Kuala Lumpur, Cheras, Malaysia. ${ }^{2}$ Hospital Sultanah Aminah, Jalan Persiaran Abu Bakar Sultan, 80100 Johor Bahru, Johor, Malaysia. ${ }^{3}$ Hospital Kuala Lumpur, 50586 Jalan Pahang, Kuala Lumpur, Malaysia. ${ }^{4}$ Hospital Tengku Ampuan Afzan, 25100 Kuantan, Pahang, Malaysia. ${ }^{5}$ Hospital Tengku Ampuan Rahimah, Jalan Langat, 41200 Klang, Kuala Lumpur, Selangor, Malaysia. ${ }^{6}$ Hospital Pulau Pinang, Residency Road, 10990 Penang, Malaysia. ${ }^{7}$ Nephrology Unit, Faculty of Medicine, Pusat Perubatan Universiti Kebangsaan Malaysia, Jalan Yaacob Latif, Bandar Tun Razak, Cheras, 56000 Kuala Lumpur, Malaysia.

Received: 31 May 2018 Accepted: 2 April 2019

Published online: 30 April 2019

\section{References}

1. Jaar BG, Chang A, Plantinga L. Can we improve quality of life of patients on dialysis? Clin J Am Soc Nephrol. 2013:8(Suppl 1):1-4.

2. Megari K. Quality of life in chronic disease patients. Health Psychol Res. 2013;1(Suppl 3):e27.

3. Wang HM, Beyer M, Gensichen J, Gerlach FM. Health-related quality of life among general practice patients with differing chronic diseases in Germany: Cross sectional survey. BMC Public Health. 2008:8:246.

4. EBPG (European Expert Group on Renal Transplantation). European Renal Association (ERA-EDTA), European Society for Organ Transplantation (ESOT). European best practice guidelines for renal transplantation (Part 1). Nephrol Dial Transplant. 2000;15:3-38

5. Sennfalt K, Magnusson M, Carlsson P. Comparison of hemodialysis and peritoneal dialysis—a cost-utility analysis. Perit Dial Int. 2002;22:39 47.

6. Abdul Manaf MR, Surendra NK, Abdul Gafor AH, Seong Hooi L, Bavanandan S. Dialysis Provision and Implications of Health Economics on Peritoneal Dialysis Utilization: A Review from a Malaysian Perspective. Int J Nephrol. 2017;2017:5819629.

7. Wong HS, Goh BL, editors. $23^{\text {rd }}$ Report of the Malaysian Dialysis and Transplant Registry. Kuala Lumpur: National Renal Registry; 2017.

8. Thomas R, Kanso A, Sedo J. Chronic kidney disease and its complications. Prim Care. 2008:32(Suppl 2):329-44.

9. World Health Organization. Global Health Estimates 2000-2015. (2015) http://www.who.int/healthinfo/global_burden_disease/estimates/en/index2. html. Accessed 28 Feb 2018.

10. Joshi VD. Quality of life in end stage renal disease patients. World J Nephro. 2014;3 Suppl 4:308-16. 
11. Malindretos P. Health Related Quality of Life in Chronic Kidney Disease Patients. J Palliat Care Med. 2012;S1:007.

12. Unruh ML, Hess R. Assessment of health-related quality of life among patients with chronic kidney disease. Adv Chronic Kidney Dis. 2007;14(Suppl 4):345-52.

13. Valderrábano F, Jofre R, López JM. Quality of life in end-stage renal disease patients. Am J Kidney Dis. 2001;38(Suppl 3):443-64.

14. Wyld M, Morton R, Hayen A, Howard K, Webster AC. A Systematic Review and Meta-Analysis of Utility-Based Quality of Life in Chronic Kidney Disease Treatments. PLoS Med. 2012;9(Suppl 9):e1001307.

15. Liu WJ, Chew TF, Chiu AS, Zaki M. Quality of life of dialysis patients in Malaysia. Med J Malaysia. 2006;61(Suppl 5):540-6.

16. Liu WJ, Musa R, Chew TF, Lim CTS, Morad Z, Bujang A. Quality of life in dialysis: A Malaysian perspective. Hemodial Int. 2014;18(Suppl 2):495-506

17. Yang F, Griva K, Lau T, et al. Health-related quality of life of Asian patients with end-stage renal disease (ESRD) in Singapore. Qual Life Res. 2015; 24(Suppl 9):2163-71.

18. Gentile S, Delarozière JC, Fernandez C, Tardieu S, Devictor B, Dussol B. Review of quality of life instruments used in end-stage renal disease. Nephrologie. 2003;24:293-301.

19. Md Yusop NB, Yoke Mun C, Shariff ZM, Beng Huat C. Factors Associated with Quality of Life among Hemodialysis Patients in Malaysia. PLoS One. 2013:8(Suppl 12):e84152.

20. Noyes J, Edward RT. EQ-5D for the Assessment of Health-Related Quality of Life and Resource Allocation in Children: A Systematic Methodological Review. Value Health. 2011;14(Suppl 8):1117-29.

21. Euroqol. EQ-5D. https://euroqol.org/. Accessed 30 Jan 2018.

22. Yusof FAM, Goh A, Azmi S. Estimating an EQ-5D Value Set for Malaysia Using Time Trade-Off and Visual Analogue Scale Methods. Value Health. 2012;3:S85-90

23. National Institute for Health and Clinical Excellence (NICE). Guide to the methods of technology appraisal. In: London: NICE; 2008

24. Hochberg MC. Updating the American College of Rheumatology revised criteria for the classification of systemic lupus erythematosus. Arthritis Rheum. 1997;40 Suppl 9:1725.

25. de Wit GA, Merkus MP, Krediet RT, de Charro FT. Health profiles and health preferences of dialysis patients. Nephrol Dial Transplant. 2002;17(Suppl 1): 86-92.

26. Bass EB, Wills S, Fink NE, et al. How strong are patients' preferences in choices between dialysis modalities and doses? Am J Kidney Dis. 2004; 44(Suppl 4):695-705.

27. De Abreu MM, Walker DR, Sesso RC, Ferraz MB. Health-Related Quality of Life of Patients Recieving Hemodialysis and Peritoneal Dialysis in São Paulo, Brazil: A Longitudinal Study. Value Health. 2011;14:s119-21.

28. Griva K, Kang AW, Yu ZL, et al. Quality of life and emotional distress between patients on peritoneal dialysis versus community-based hemodialysis. Qual Life Res. 2014;23(Suppl 1):57-66.

29. Harris SA, Lamping DL, Brown EA, Constantinovici N. Clinical outcomes and quality of life in elderly patients on peritoneal dialysis versus hemodialysis. Perit Dial Int. 2002;22:463-70

30. Manns B, Johnson JA, Taub K, Mortis G, Ghali WA, Donaldson C. Quality of life in patients treated with hemodialysis or peritoneal dialysis: what are the important determinants? Clin Nephrol. 2003:60(Suppl 5):341-51.

31. Peng YS, Chiang CK, Hung KY, et al. Comparison of self-reported healthrelated quality of life between Taiwan hemodialysis and peritoneal dialysis patients: a multi-center collaborative study. Qual Life Res. 2011;20:399-405.

32. Wasserfallen JB, Halabi G, Saudan P, et al. Quality of life on chronic dialysis: comparison between hemodialysis and peritoneal dialysis. Nephrol Dial Transplant. 2004;9(Suppl 6):1594-9.

33. Wu AW, Fink NE, Marsh-Manzi JV, et al. Changes in Quality of Life during Hemodialysis and Peritoneal Dialysis Treatment: Generic and Disease Specific Measures. J Am Soc Nephrol. 2004;15(Suppl 3):743-53.

34. Liem YS, Bosch JL, Hunink M. Preference-Based Quality of Life of Patients on Renal Replacement Therapy: A Systematic Review and Meta-Analysis. Value Health. 2008;11(Suppl 4):733-41.

35. Atapour A, Nasr S, Boroujeni AM, Taheri D, Dolatkhah S. A comparison of the quality of life of the patients undergoing hemodialysis versus peritoneal dialysis and its correlation to the quality of dialysis. Saudi J Kidney Dis Transpl. 2016:27:270-80.

36. Ginieri-Coccossis M, Theofilou P, Synodinou C, Tomaras V, Soldatos C Quality of life, mental health and health beliefs in hemodialysis and peritoneal dialysis patients: Investigating differences in early and later years of current treatment. BMC Nephrol. 2008;9(Suppl 14):1-9.

37. Kutner NG, Zhang R, Barnhart H, Collins AJ. Health status and quality of life reported by incident patients after 1 year on hemodialysis or peritoneal dialysis. Nephrol Dial Transplant. 2005;20(Suppl 10):2159-67.

38. Makkar V, Kumar M, Mahajan R, Khaira NS. The Comparison of Quality of Life among Peritoneal and Hemodialysis Patients. J Clin Diagn Res. 2015;9(Suppl 3):OC28-31.

39. Theofilou P. Quality of Life in Patients Undergoing Hemodialysis or Peritoneal Dialysis Treatment. J Clin Med Res. 2011;3(Suppl 3):132-8.

40. Al Wakeel J, Al Harbi A, Bayoumi M, Al-Suwaida K, Al Ghonaim M, Mishkiry A. Quality of life in hemodialysis and peritoneal dialysis patients in Saudi Arabia. Ann Saudi Med. 2012;32(Suppl 6):570-4

41. Diaz-Buxo JA, Lowrie EG, Lew NL, Zhang H, Lazarus JM. Quality-of-life evaluation using Short Form 36: comparison in hemodialysis and peritoneal dialysis patients. Am J Kidney Dis. 2000;35(Suppl 2):293-300.

42. Aghakhani N, Sharif Nia H, Samad Zadeh S, Toupchi V, Toupchi S, Rahbar N. Quality of life during hemodialysis and study dialysis treatment in patients referred to teaching hospitals in Urmia-Iran in 2007. Caspian J Intern Med. 2011;2(Suppl 1):183-8.

43. Lopes AA, Bragg-Gresham JL, Goodkin DA, et al. Factors associated with health-related quality of life among hemodialysis patients in the DOPPS Qual. Life Res. 2007;16(Suppl 4):545-57.

44. Finkelstein FO, Story K, Firanek C, et al. Health-Related Quality of Life and Hemoglobin Levels in Chronic Kidney Disease Patients. Clin J Am Soc Nephrol. 2009:4(Suppl 1):33-8.

45. Sakthong P, Kasemsup V. Health utility measured with EQ-5D in Thai patients undergoing peritoneal dialysis. Value Health. 2012;15(Suppl 1): S79-84.

46. Eriksson D, Goldsmith D, Teitsson S, Jackson J, van Nooten F. Cross-sectional survey in CKD patients across Europe describing the association between quality of life and anaemia. BMC Nephrol. 2016;17:97.

47. Pagels AA, Söderkvist BK, Medin C, Hylander B, Heiwe S. Health-related quality of life in different stages of chronic kidney disease and at initiation of dialysis treatment. Health Qual Life Outcomes. 2012;10:71.

48. Locatelli F, Pozzoni P, Tentori F, Del VL. Epidemiology of cardiovascular risk in patients with chronic kidney disease. Nephrol Dial Transplant. 2003;18:12-9.

49. United States Renal Data Systems (USRDS). 2017 Annual Data Report. (2018) https://www.usrds.org/adr.aspx. Accessed 25 Apr 2018.

50. Forman-Hoffman $V L$, Ault $K L$, Anderson WL, Weiner JM, Stevens A, Campbell VA, Armour BS. Disability Status, Mortality, and Leading Causes of Death in the United States Community Population. Med Care. 2015:53(Suppl 4):346-54.

51. Krahn GL, Walker DK, Correa-De-Araujo R. Persons with Disabilities as an Unrecognized Health Disparity Population. Am J Public Health. 2015; 105(Suppl 2):S198-206.

52. Knies S, Evers SM, Candel MJ, Severens JL, Ament AJ. Utilities of the EQ-5D: Transferable or not. Pharmacoeconomics. 2009;27(Suppl 9):767-79.

53. Endarti D, Riewpaiboon A, Thavorncharoensap M, Praditsitthikorn $N$, Hutubessy R, Kristina SA. A Comparison of EQ-5D-3L Index Scores Using Malaysian, Singaporean, Thai, and UK Value Sets in Indonesian Cervical Cancer Patients. Value Health Reg Issues. 2018;15:50-5.

54. Kiadaliri A, Eliasson B, Gerdtham UG. Does the choice of EQ-5D tariff matter? A comparison of the Swedish EQ-5D-3L index score with UK, US, Germany and Denmark among type 2 diabetes patients. Health Qual Life Outcomes. 2015;13:145

55. Zhao Y, Li S-P, Liu L, Zhang J-L, Chen G. Does the choice of tariff matter? A comparison of EQ-5D-5L utility scores using Chinese, UK, and Japanese tariffs on patients with psoriasis vulgaris in Central South China. Medicine (Baltimore). 2017:96 Suppl 34:e7840. 